\title{
Representaciones y literatura oral acerca del Demonio en los municipios de Amacueca y Tapalpa, en el sur de Jalisco
}

\section{Representations and oral literature about the Demon in the municipalities of Amacueca and Tapalpa, in southern Jalisco}

\author{
Víctor Manuel Bañuelos Aquino \\ (Universidad de Guadalajara) \\ banuelosaquino@gmail.com \\ ORCID ID: 0000-0002-0630-0536
}

ABSTRACT: The southern region of the state of Jalisco, Mexico, is an area that, due to its varied topography, has been the focus of diverse tourist activities, mainly due to the pitahaya and nut festivities that are celebrated along with other religious festivities. Of course, as there are flows of people because of tourism or participation in this type of festival, there has been interaction between various groups of people who have introduced and appropriated various stories around the appearance of the Devil, in this case a being that it appeared to travelers during the nights. Based on the above, some stories about these demonic manifestations will be exposed and analyzed, with a main emphasis on two representations of this region, which for the understanding of issues of Novo-Hispanic folklore will not fail to attract attention: The Devil riding a horse and the Demon Like a black bull with red eyes.

KeYwordS: Folklore, oral literature, Diablo in Mexico, popular legends, comparative mythology
Resumen: La región sur del estado de Jalisco, México, es una zona que por su variada topografia ha sido foco de diversa actividad turística, principalmente por las fiestas de la pitahaya y la nuez que se celebran junto con otras festividades religiosas. Por supuesto, al existir flujos de personas por causa del turismo o la participación en este tipo de festivales, se ha producido la interacción entre diversos grupos de personas que han introducido y apropiado diversos relatos en torno a la aparición del Diablo, en este caso un ser que se aparecía a los viajeros durante las noches. Partiendo de lo anterior, se expondrán y analizarán algunos relatos sobre estas manifestaciones demoniacas, poniendo principal énfasis en dos representaciones de esta región, que para el entendido en temas del folclor novohispano no dejará de llamar la atención: el Diablo montando a caballo y el Demonio como un toro negro de ojos rojos.

Palabras-Clave: Folclor, literatura oral, Diablo en México, leyendas populares, mitología comparada 
A MANERA DE INTRODUCCIÓN: ACERCA DE UNA REGIÓN FOLCLÓRICA DE JALISCO

Como el título de este ensayo lo sugiere, en el presente trabajo se analizarán algunas leyendas que tienen como protagonista al Diablo en la región sur del estado de Jalisco, en México ${ }^{1}$. Estos relatos se registraron en formato de audio el día 29 de diciembre de 2019 en los municipios de Tapalpa y Amacueca, a partir de entrevistas realizadas a tres informantes oriundos de la zona.

Las características de esta región y sus principales actividades económicas generan, hasta el día de hoy, la movilización de un gran número de personas durante distintas épocas del año. Las actividades económicas más rentables de la zona son la venta de artículos como la nuez, el fruto de la pitahaya y el café, mismos que desde hace numerosas décadas son vendidos en las fiestas religiosas de los diversos pueblos que componen los municipios de Tapalpa y Amacueca, los dos en los que nos detendremos en este breve ensayo. Sin embargo, a pesar de la similitud que existe en las condiciones mercantiles de estos municipios, no será a partir de sus modelos económicos que delimitaremos la región que queremos analizar, ya que al ser más bien la cuestión de sus imaginarios religiosos en la que nos queremos centrar, haremos una delimitación espacial desde la perspectiva de los estudios de la narrativa tradicional mexicana.

Existen diversas maneras de seccionar un estado en regiones. Por lo general se suele hacer esta separación en torno a sus actividades económicas representativas, sin embargo, para nuestros efectos, lo haremos a través de la teoría de las regiones folclóricas. Cuando nos damos cuenta que un grupo de comunidades crean una suerte de identidad propia, a partir de sus tradiciones culturales y sus constructos religiosos y del imaginario, nos percatamos de que estas están conformando una suerte de región folclórica, es decir, una en la que las personas que la constituyen comparten creencias y formas artísticas gracias a que tienen un pasado y unas condiciones de vida en común (Zavala Gómez del Campo, 2013: 29-36). Estos elementos comunes que forjan una identidad son los que a su vez componen los temas y motivos que se manifiestan en la literatura regional, al cual pertenece este corpus de literaturas orales, en los que las raíces tradicionales dotan de una carga semántica, reconocible por los habitantes de la región, estas leyendas y tradiciones populares (Martínez Morales, 2006: 11-12).

Aplicando estos razonamientos teóricos a nuestro objeto de estudio, podemos ver diversas tradiciones compartidas entre los pobladores tanto de Tapalpa como de Amacueca, tomando en cuenta sus leyendas, en este caso particular un pequeño corpus de ellas en las que se describe la manera en que se interpreta a la figura del Diablo en esta zona mexicana, derivada dicha representación de las costumbres y condiciones materiales que tienen en común los habitantes de esta región y que nos ayuda a ver en este espacio del sur de Jalisco una región folclórica, en la que se representa al Demonio a partir de la experiencia de vida cotidiana de los viajeros y mercaderes que se movían constantemente entre los municipios de Tapalpa y Amacueca, en ocasiones de noche, la tradición compartida que hace que estas leyendas se cuenten de modo semejante en estos dos municipios, y con probabilidad en otros aledaños, en donde además aparecen personas y lugares identificables por aquellos que cuentan estos relatos, denotando una vez más un marco de referencia común.

\footnotetext{
${ }^{1}$ Este es un estado ubicado en la zona occidental mexicana, con una costa colindante al océano Pacífico. Su capital es la ciudad de Guadalajara, la segunda más grande del país, solo después de la descomunal Ciudad de México. El estado tiene una gran diversidad de ecosistemas que permite que, así como en su zona centro haya un clima templado, tenga a su vez uno de carácter montañoso en su parte sur, en aquella en la que nos vamos a centrar.
} 


\section{LAS REPRESENTACIONES DEL Diablo}

En la región folclórica que hemos delimitado, en el sur de Jalisco, existen diversas manifestaciones del Demonio que, si bien no son privativas de esta región ya que formalmente mantienen un parecido con otras figuraciones del Diablo de otras regiones de México y el mundo, se puede especular que están inspiradas en las vivencias de diversas personas que viajaban por las noches entre estas comunidades, las cuales comparten estos relatos populares por temer a ciertos lugares bien reconocibles por tradiciones más antiguas, como se verá en un ejemplo a continuación. Tomando en cuenta las narraciones que nos han proporcionado nuestros tres informantes, podemos reconocer las manifestaciones del Demonio a partir de tres tópicos:

1. Su manifestación como un hombre que monta un caballo.

2. Su manifestación como un viento demoniaco que daña a las personas.

3. Su manifestación como un toro negro de ojos rojos que huele a azufre.

Sobre las narraciones que veremos a continuación, cabe mencionar que las dos primeras son acerca de un mismo relato, en el que las visitantes a un cerro maldito sufren la presencia del Demonio, manifestándose este como un viento demoniaco que llena de terror al que lo siente, según el folclor de la gente de Tapalpa. En un segundo momento apreciaremos en otro relato, este del municipio de Amacueca, la aparición del Diablo como un formidable toro negro. En ambos casos se aprecia el miedo que despertaba la noche en un contexto boscoso, en el que los habitantes de esta región materializaron estos miedos en este personaje del imaginario religioso.

De manera que, para tener mayor claridad expositiva, a continuación, se analizarán los dos relatos por separado, tomando en cuenta sus características y la manera en que pueden ser asociados a otros relatos semejantes de otras regiones de México y del mundo.

\section{EL DIABLO A CABALLO}

El Demonio como figura del cristianismo ha sufrido diversas transformaciones, siempre con base en las problemáticas y temores de una comunidad, convirtiéndose en diversos momentos históricos en la materialización de los miedos sociales. Este personaje del sistema religioso del cristianismo se fue construyendo de manera lenta y gradual durante los siglos que duró el medioevo, obteniendo su forma y oficialidad dentro de la teología católica durante este período histórico, cuando se llegó a un consenso de su representación, características y papel dentro de la cosmovisión cristiana, al conjuntar en su figura una serie de elementos iconográficos y motivos literarios de diversas entidades del imaginario pagano que fueron asociados a distintas entidades malignas del Antiguo y el Nuevo Testamento (Muchembled, 2012: 19-20).

De manera posterior, fue introducido en la Nueva España, como parte del discurso de la evangelización, en donde se asoció a los dioses de los moradores autóctonos con las representaciones más estereotipadas del Demonio barroco, siendo perceptible en la cultura novohispana en diversos soportes de la tradición popular que van desde los relatos orales hasta las declaraciones hechas por supuestos idólatras ante los tribunales religiosos de la Nueva España (Ayala Calderón, 2010: 107-136). En el caso mexicano y más puntualmente del estado de Jalisco, la figura del Demonio se ha asociado a la del Charro Negro, una suerte de jinete ricamente ataviado de negro que se aparece por las 


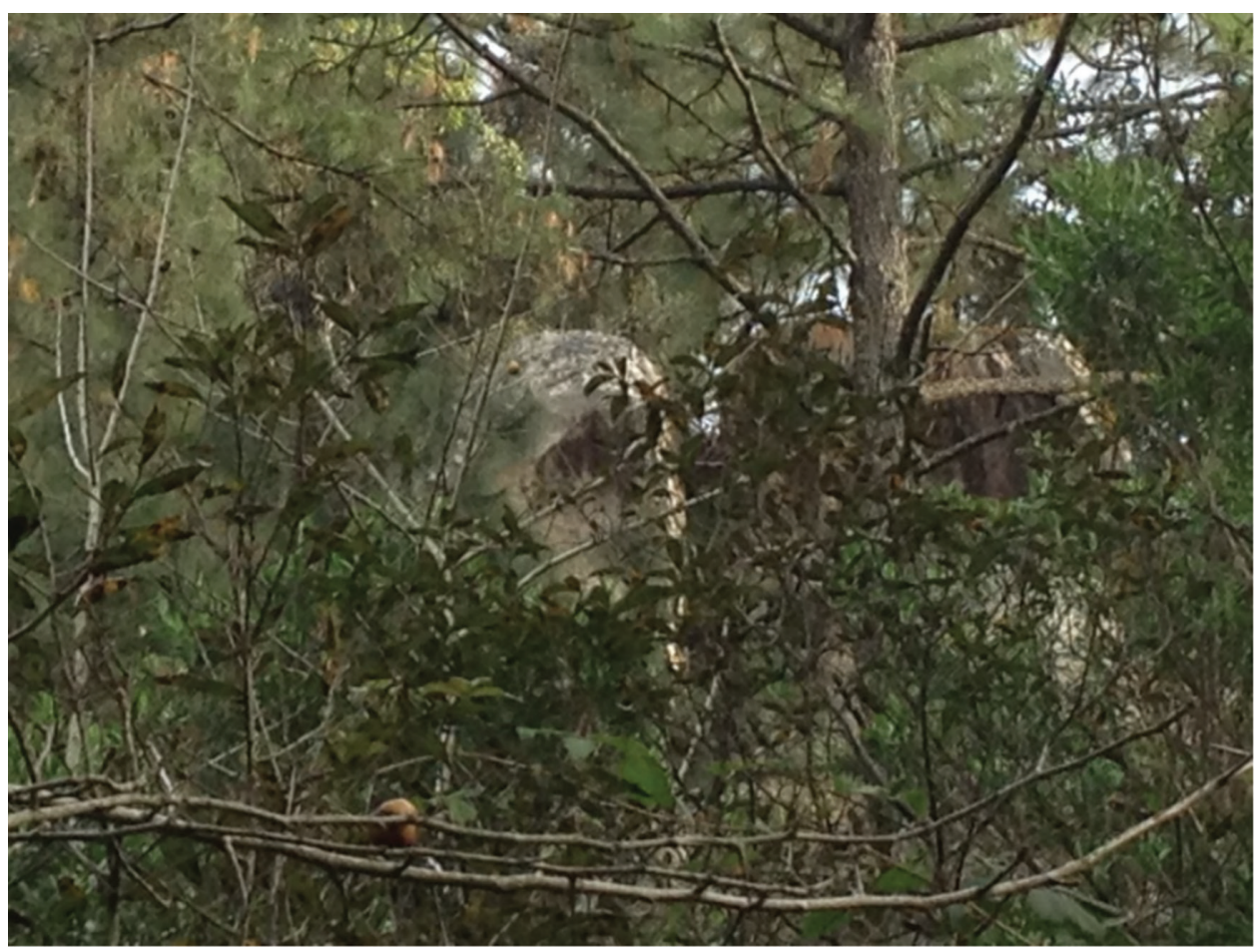

Figura 1: Cerrito de Talcozagua, vista desde la carretera en la que se aprecian las formaciones rocosas que hacen en parte famoso al lugar. Foto tomada el 21 de diciembre de 2015.

noches y realiza diversas actividades, mismas que van desde los intercambios de almas hasta el robo de jovencitas que lleva directamente al Infierno (Ramírez González, 2014: 156-157).

Ahora bien, en el municipio de Tapalpa existe una tradición, puesto que su narración no guarda la estructura formal de un relato con un inicio y un final (Briggs, 2019: 21), según la cual en el cerrito de Talcozagua (ver figura 1) se aparece el Demonio montando a caballo. Existen diversas versiones: o bien se aparece sobre las rocas del cerrillo o algunas de estas toman la forma del Diablo al atardecer. Se cree que en este lugar han ocurrido cosas horrendas desde tiempos inmemoriales, es decir, previas a la conquista española del lugar. Finalmente, las habladurías y rumores dicen que la aparición del Demonio en este cerrito precede sucesos desgraciados.

Se cuenta que los que viajan al poblado de Tapalpa, Jalisco, considerado atractivo turístico por su topografía montañesa rodeada de bosques, pueden encontrarse con el cerrito de Talcozagua, un lugar maldito en el que se piensa que el Diablo hace acto de presencia. A continuación, reproduzco íntegramente un suceso que se cuenta ocurrió en este lugar de Talcozagua en la década de los 1970. La entrevistada es profesora de nivel básico en el poblado de Tepec, Amacueca, la cual es depositaria de los rumores populares del poblado, uno en el que debido a la venta de productos como la nuez y la pitahaya existe una gran movilidad de mercaderes que suelen relatar sucesos extraños que ven o escuchan, y que forman parte del folclor de esta región mexicana, razón por la que a pesar de que la entrevistada no es de Tapalpa nos cuenta un relato de ese lugar:

Soy Ana María Velazco Rodríguez, soy educadora durante cuarenta y ocho años de mi vida, he vivido muchas experiencias, pero algo muy significativo fue la ida a un lugar 
llamado Talcozagua a donde fuimos a recoger piñitas [por su naturaleza montañosa en el cerro de Talcozagua se dan pinos y árboles que arrojan semillas de conífera conocidas como piñas] para adornar el arbolito de Navidad. Es un lugar, en donde menciona mucha gente que ha aparecido el Demonio, nosotros no vimos nada de eso, bendito sea Dios, pero fue una experiencia dura: estábamos recogiendo las piñitas cuando un viento frío, muy frío, empezó a azotarnos y enseguida, empezamos a sentir una vibra muy fuerte, un viento cargada de malas vibraciones.

Tuvimos miedo y empezamos a caminar y caminar, pero el ruido, el eco, se llevaba el sonido, el sonido a donde íbamos. Miriam, se puso mala mi hija, se le taparon los oídos, y ya estaba atardeciendo, ya atardecía, y mientras más nos alejábamos el sonido nos iba siguiendo. Nosotros asociamos ese sonido, primero, a los cables de la luz, pero vimos que no había; después lo asociamos, al... al viento, que en ese momento hacía un sonido muy diferente porque era un sonido que te daba miedo, que te estremecía.

Duramos un largo rato esperando un camión que nos trajera aquí al poblado [estaban en Talcozagua, Tapalpa, y tenían que regresar a Tepec]... nada. Por la gracia de Dios había un compañero ahí, de la escuela, que él mismo nos cuestionó: «¿Qué andan haciendo aquí a esta hora? Esta es una zona peligrosa en todos los aspectos», y él fue el que nos trajo.

Dicen que este [Talcozagua] es un lugar donde el Diablo está muy, pero muy, pero muy aposentado ahí en una roca, que le gusta el lugar, y hay un lugar, es un lugar de frecuentes accidentes, ahí son frecuentes los accidentes. Es una línea recta, que no tiene que haber accidentes, pero hay frecuentemente, ahí verás sí subes muchas cruces porque hay muchos accidentes. El lugar de por sí te estremece, al bajar simplemente, sientes un viento muy diferente al que es usual, es un viento que... que atrae miedo, porque has de cuenta que el viento atrae otro sonido, un sonido que te espanta... pero ese viene del viento, porque, aunque hasta las rocas están cubriendo pues que el viento no te dé con fuerza sí te llega. Las mismas ramitas de los pinos tiemblan con ese viento.

No sé por qué no lo han encontrado ese lugar muchas personas, pero la verdad... este espanta, asusta, te hace cuestionarte si hay otra dimensión o qué pasa, el viento surge en el momento cuando tú no esperas y te lastima hasta los oídos. No sé si tú nunca has subido ahí cerca de esas rocas... pero es un sitio donde se siente... malas vibras, se sienten malas vibras. $^{2}$

Una versión un tanto distinta de este mismo relato nos ofrece una visión un poco más burlona del Demonio, que se aleja de la descripción siniestra y aterradora que de este se hiciera en el testimonio anterior. La entrevista fue realizada a otra profesora de primaria del mismo poblado de Tepec, la cual desempeñó esta labor por décadas y llegó a laborar en cargos públicos como el de regidora. En esta versión nuevamente se insiste en el viento maligno que actúa como una suerte de manifestación del Diablo:

Estábamos todavía trabajando en Tepec, e íbamos a la sierra a recoger piñas para la Navidad, entonces mi mamá y Miriam, después de que salieron por la tarde de la escuela tomaron el camión de las siete, fijate era ya tarde. Subieron hasta... Talcozagua que quiere decir: «el Diablo a caballo» y este... había ocurrido exactamente ahí, en Talcozagua, un accidente de tránsito: un camión se accidentó y hubo muchos muertos, y curiosamente exactamente ahí en ese lugar había, se dejaron que había una especie de sepultura, estaba la tierra fresca... y estaban ellas comentando que se veían vidrios rotos, y bueno... efectos del accidente, cuando se oyó un ruido espantoso... Miriam se asustó muchísimo.

\footnotetext{
${ }^{2}$ Informó: Ana María Velazco Rodríguez, maestra de primaria, originaria de Tepec, Amacueca, residente de Guadalajara, 72 años. Recogió: Víctor Manuel Bañuelos Aquino. Versión en línea de la grabación y la transcripción en la página web: https://corpusdeliteraturaoral.ujaen.es/archivo/799n-el-diablo-caballo.
} 
Casualmente iba un arriero de Tepec, Don Vicente Mesa, y mi mamá empezó a decir cosas de pues... el Diablo a caballo ¿no? Y diciendo que... maldiciendo pues al Diablo, y le dijo este, el indígena, Don Vicente: « ¡No doña Hilde! [el nombre de la aludida] ¡no, no, no diga nada de él! Porque sí no mire mis burros me los va a espantar. Mire, en una ocasión que se me ocurrió decir unas palabras en contra de él duré tres días, porque mis burros se fueron, partieron a la carrera por entre la sierra y tres días me costó de trabajo localizarlos».

Y ya estaba oscureciendo, y ya no había camión para regresar, yo no sé qué pensaron mi mamá y este... Miriam, porque iban a pie por la carretera, rumbo a Tepec, a qué, ¿a qué horas iban a llegar? Casualmente pasó un maestro, un maestro de Tapalpa que iba rumbo a Sayula y reconoció a mi mamá y dijo: «maestra Hilde i¿qué anda haciendo a estas horas y aquí?!», en Talcozagua, toda la gente le tiene horror a ese lugar. Ahí se aparece el Diablo, y hace como su nombre lo indica, muchas diabluras, diabluras como exactamente lo que dijo el arriero: que le espantaba a sus burros y que después para hallarlos era un trabajo, de ese tipo, no pasaba a más... jajaja, no pasaba a más. ${ }^{3}$

Al observar las dos narraciones nos damos cuenta de que hablan del mismo acontecimiento, ocurrido en el cerrito de Talcozagua y del cual dan fe diversas autoridades de la zona, por la participación de profesores y arrieros conocidos en el poblado de Tepec. En los dos relatos existe un remanente de la tradición occidental, introducida a la Nueva España por intermediación de los conquistadores españoles, que le confería a la figura del Diablo una doble naturaleza: una cómica y otra aterradora, que también es visible en el imaginario novohispano (Carranza Vera, 2014: 138 y 155-156), ya que si bien el Diablo es capaz de aparecerse en un lugar marcado por diversas tragedias, y manifestarse de manera aterradora, a su vez también es el autor de diversas fechorías que recuerdan la acción de los duendes y otros entes feéricos de diversas tradiciones.

Acerca de estas historias, se sabe que sucesos como los antes narrados suelen tomarse como relatos extraídos de la realidad, por lo que son tomados por ciertos por los habitantes de una región (Briggs, 2019: 17), en nuestro caso la región folclórica del sur de Jalisco, razón por la que es común que diversas personas al contar anécdotas de su pasado, suelan tomar esta clase de esquemas narrativos para resignificar diversas vivencias pretéritas.

Para finalizar con este apartado, en el folclor del estado de Jalisco se suele representar a la figura del Demonio como un charro negro (Ramírez González, 2014: 156-157), personaje que guarda una enorme similitud formal con el Diablo a caballo de Talcozagua, y que tiene mucha presencia en relatos folclóricos y tradicionales de todo el estado. Con mucha probabilidad, la recurrencia de este personaje en este contexto se debe a lo fuertemente arraigada de la imagen del charro en esta parte del país, mismo que sigue existiendo en clubes y espacios en los que se practica el deporte de la charrería en el que hombres y mujeres ricamente ataviados realizan toda clase de proezas temerarias con un lazo - llamado riata- y montando a caballo, ya que este pertenecía a uno de los últimos rezagos de la aristocracia pre revolucionaria, común en las otrora zonas hacendarias y que en el pasado pudo haber sido visto como una figura opresora y terrorífica por algunos de los campesinos que trabajaban para ellos.

\footnotetext{
${ }^{3}$ Informó: Silvia López Bañuelos, maestra de primaria, originaria de Tepec, Amacueca, residente de Guadalajara, 84 años. Recogió: Víctor Manuel Bañuelos Aquino. Versión en línea de la grabación y la transcripción en la página web: https://corpusdeliteraturaoral.ujaen.es/archivo/800n-el-diablo-caballo.
} 


\section{EL TORO NEGRO}

El toro negro como manifestación del Diablo ha gozado de cierta popularidad en diversas regiones de México. Se observa un ejemplo de ello en la obra de Enrique Flores y Mariana Masera, Relatos populares de la Inquisición novohispana, en la que se aprecia cómo en determinada documentación inquisitorial, ciertos procesados testificaron haber visto al Demonio aparecer bajo esta forma, ya que en la tradición hispánica y posteriormente en la novohispana se creía que los arrieros eran propensos al uso de la magia maligna (Flores y Masera, 2010: 37-40), probablemente por la cercanía que estos personajes tenían con la naturaleza y los espacios agrestes donde, desde la Edad Media, se pensaba que el Diablo tenía sus dominios (Michelet, 2009: 58-59).

Esta visión del toro como una entidad representativa de las fuerzas del caos, y del mal en la cosmovisión del sistema religioso del cristianismo, viene de antaño. En diversas de sus obras la historiadora Cristina Delgado Linacero explicó que el tamaño, poder y fuerza de este bóvido lo hizo un símbolo polisémico que fue utilizado de modo ambivalente en distintas culturas: tanto por algunas familias aristocráticas de Oriente y de Egipto que veían en este animal una insignia del poder asociado a la nobleza (Delgado Linacero, 2007: 93-98); como también, en relatos mitológicos, en los que era visto como un monstruo caótico y maléfico para la humanidad (Delgado Linacero, 1996: 379-380). De manera que no será extraño que en diversas culturas y a lo largo de la historia este animal haya aparecido en una gran cantidad de relatos folclóricos.

En un ejemplo más concreto y cercano a nuestro objeto de estudio, en el actual estado de Jalisco vemos el caso de los Hechiceros de Tomatlán (1760-1761), ${ }^{4}$ una serie de folios que hablan del caso del indio Chanfaro y los supuestos hechiceros Juan Serrano y Julio de Santiago. Lo llamativo de este documento, para nuestra investigación, es que narra la manera en que este grupo se reunía con Satán en un monte de las proximidades, en donde este aparecía aparentemente bajo la forma de un toro negro que despedía un fuerte olor a azufre. Según el documento, con el uso de ciertas imágenes sagradas el indio Chanfaro pretendía convertirse en un excelente vaquero con la capacidad de cautivar a cualquier mujer «aún delante de sus maridos». ${ }^{5}$ Sin embargo, para poder hacer uso pleno de los poderes mágicos de la imagen debía realizar una suerte de ritual de hechicería, en el cerro del Pueguenton o en el de Fragoso, lugares cercanos al asentamiento de Tomatlán donde ocurrió la narración. Julio Santiago, otro de los hechiceros, le hizo la advertencia de que al ir a alguno de estos lugares no debía llevar ni cruces ni rosarios y que debía ir de noche, pues de lo contrario el hechizo no surtiría efecto. ${ }^{6}$ El ritual que a continuación debía realizarse era complejo:

1. Primero: debían subir a alguno de los cerros antes mencionados con un chivo al que debían de picar con una púa.

2. Segundo: debían permitir que una serpiente les lamiera los pies.

3. Tercero: evitar la embestida de un toro negro que estaría arriba de uno de los montes.

4. Cuarto: debían subir al monte en un caballo y bajarlo montando una mula. ${ }^{7}$

\footnotetext{
${ }^{4}$ AHAG, Sección justicia, vol. 1, exp. 16, fs. 1-22.

${ }^{5}$ AHAG, Sección justicia, vol. 1, exp. 16, f. 2.

${ }^{6}$ AHAG, Sección justicia, vol. 1, exp. 16, f. 2 r.

${ }^{7}$ AHAG, Sección justicia, vol. 1, exp. 16, f. 2 r.
} 


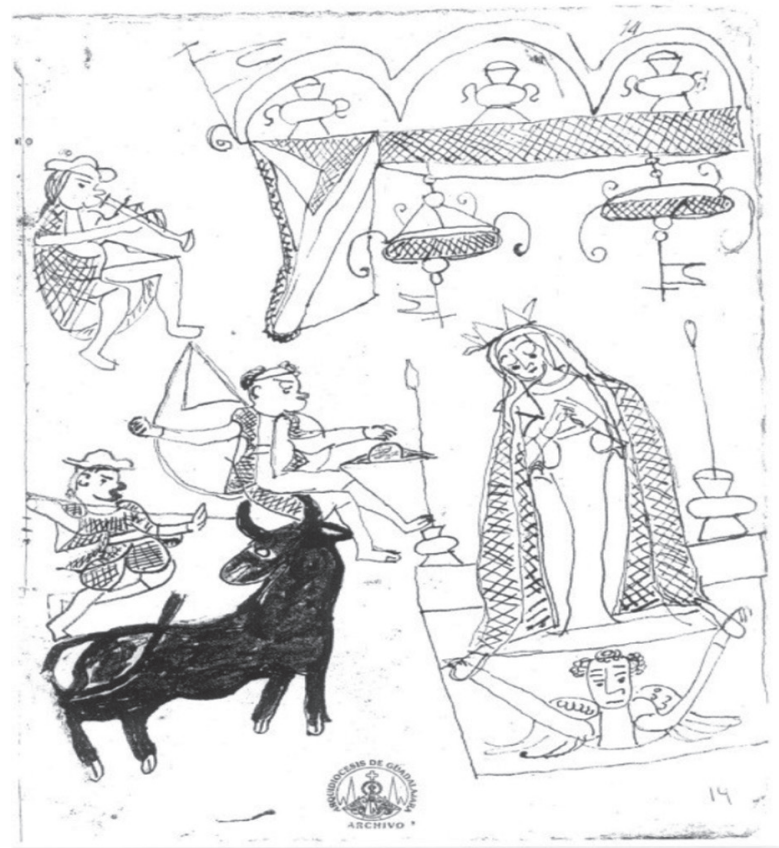

Figura 2: Imagen del toro negro del caso de los Hechiceros de Tomatlán presuntamente realizada por el agente del tribunal eclesiástico ordinario del Obispado de Guadalajara, Marcos Montes de Oca. Archivo Histórico de la Arquidiócesis de Guadalajara (AHAG), Sección justicia, vol. 1, exp. 16, f. 14.

En su declaración, ante el tribunal eclesiástico ordinario, Chanfaro explicó que por miedo prefirió abstenerse de ir. No obstante, narró que tiempo después acompañó a su camarada Julio de Santiago al rancho de la Lagunilla donde, en el camino, le salió al encuentro un toro negro que le hizo sentir mucho miedo. Dice en su testimonio que su acompañante, Julio de Santiago, se acercó al animal y lo invitó a tocarlo, aunque se negó de forma reiterada. Súbitamente, el toro desapareció, dejando en su lugar un fuerte olor a azufre. Tras esta experiencia Julio le aseguró que era capaz de invocar más toros. Así lo describe el testimonio del procesado según la documentación del tribunal eclesiástico ordinario del obispado de Guadalajara:

Una noche Chanfaro, en compañía de Julio de Santiago del rancho de la Lagunilla, para el de la Barranquilla, ambos de esta jurisdicción [se refiere a Tomatlán], y que dicho Julio de Santiago le dijo al dicho Chanfaro que le había dejado un toro, y a poco andar salió el toro, y le dijo Julio de Santiago a Chanfa[ro], que se apeara a torearlo, y declara el dicho Chanfa[ro], que le hubo miedo dicho toro por lo que no quiso tocarlo sino que antes se volvió para atrás y se mantuvo, distante de donde estaba largo rato, hasta que Jul. de Santiago le llamó diciéndole que ya se había ido el toro entonces siguió su camino a alcanzar a dicho Julio de Santiago y habiendo llegado al lugar donde estuvo el toro percibió mucho hedor a azufre, y habiendo seguido su camino para donde iban a poco rato le dijo Jul. de Santiago a Chanfa[ro] que sí quería que saliera otro toro a lo que dice que le respondió, que no. ${ }^{8}$

Este relato, así como algunos de los otros que componen este caso, está acompañado de una ilustración hecha presuntamente por Marcos Montes de Oca, el oficial encargado

${ }^{8}$ AHAG, Sección justicia, vol. 1, exp. 16, f. 2r. 
de llevar las pesquisas de este caso tan peculiar (ver figura 2). En este caso del tribunal eclesiástico ordinario, vemos una vez más reiterado ese imaginario novohispano en el cual se creía que existía un vínculo entre los arrieros y la magia maligna

A pesar de la distancia temporal y espacial, ya que Tomatlán -el lugar del acontecimiento previamente narrado- está ubicado cerca de la costa que tiene el estado de Jalisco con el océano Pacifico, vemos que en su región sur también existe una tradición similar en torno a un toro negro demoniaco, ya que este motivo folclórico aparece en uno de los ejemplos mencionados por el tercero de nuestros narradores. Este relato nos lo proporcionó José Figueroa, oriundo del pueblo de Tepec, conocido entre sus vecinos con el alias de: El Soberano, porque la gente de las cercanías le atribuye una serie de vivencias en las que estuvieron involucradas la magia y elementos del mundo preternatural, hechos tales como el haber pactado con la muerte, ver al Diablo y sobrevivir al impacto de un rayo, como él mismo nos explicó en una entrevista realizada en el año 2016.

En el poblado de Tepec, en el municipio de Amacueca, Jalisco, existe la leyenda de un toro negro que asusta a los transeúntes al atardecer. En esta grabación realizada el día 29 de diciembre de 2019, José Figueroa, de 92 años, oriundo de la zona y considerado como un narrador por la gente del pueblo, nos compartió una experiencia propia en la que comenta haber visto a esta suerte de manifestación demoniaca:

Fue en la tarde, no era noche, fue en la tarde, y ya venía yo con mi, mmm, mandado aquí [hace señal como si cargara algo cerca del pecho], dado vueltas en papel, y lo traía aquí, y ahí vengo caminando pues, al paso, porque no podía correr, y ya de un de repente... alce a ver y voy viendo ese animal... un... un buey, pero grande, como de aquí a donde está la parte esa [señala con las manos el espacio que abarca desde donde estamos hasta un muro alejado a algunos metros de nosotros], y ancho que abarcaba todo el, todo el camino, y con unos cuernos de aquí a aquí [simula con los brazos extendidos el tamaño aproximado de la cornamenta]... y luego los ojos así, como un tizón en cada lado... rojo.

Y pues de momento, al verlo así, pues me atacó. Querer... pues ya no pude hablar ni nada, nomás... nomás quería pues pronunciar... alguna cosa o... para defenderme, pues nomás estaba pujando: ummm, ummm y le hacía la lucha para pasar, y me aventaba una cornada, y entonces yo me sacaba y le daba vuelta por el otro lado, y así me llevaba. Pero, pero no me... que digamos, que me hubiera hecho mal en el cuerpo no... pues sí trató y todo eso, pero la... miedo no me llegó, nada, y entonces este... cuando ya iba pues caminó un buen rato toreándolo: yo quería pasar, pero él no dejaba, y entonces en una de esas ya pude, ya nomás dije: «Ave María Purísima sin pecado te han concebido», y en un agujerito así de una cerca [hace la forma de un pequeño agujero con sus dedos], como una sombra, así se metió por ahí todo y se fue...desapareció... son espíritus diabólicos... se fue por ahí entre las piedras de la cerca... como que lo iban jalando pues. ${ }^{9}$

Esta narración nos muestra un ejemplo más de este antiguo miedo taurino, en este caso reconfigurado con respecto a las realidades contextuales de la región sur de Jalisco en el que aparecen elementos autóctonos, como seguramente ocurre en cada espacio en el que este animal y el folclor alrededor a él es introducido, enriqueciendo de este modo esta figura del imaginario, de acuerdo a las condiciones materiales del

\footnotetext{
${ }^{9}$ Informó: José Figueroa, campesino, originario de Tepec, Amacueca, residente de Tepec, 91 años. Recogió: Víctor Manuel Bañuelos Aquino. Versión en línea de la grabación y la transcripción en la página web: https://corpusdeliteraturaoral.ujaen.es/archivo/801n-el-toro-negro-de-tepec.
} 


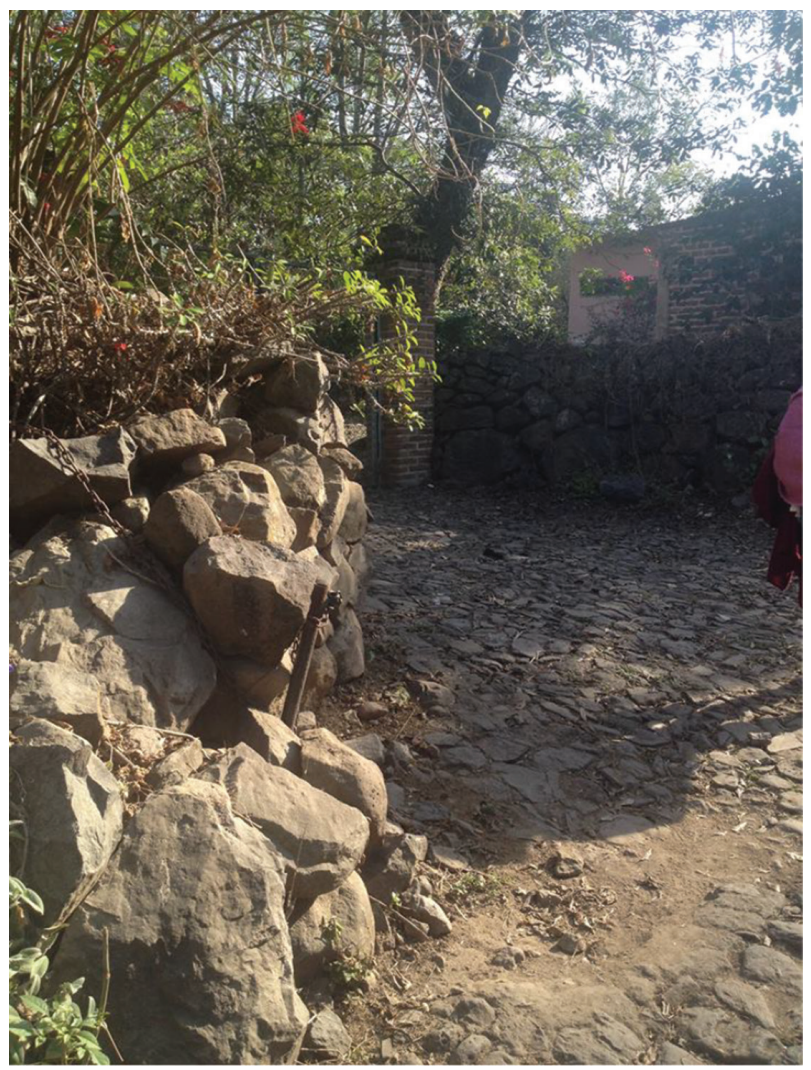

Figura 3: En este lienzo de piedras, antes tan comunes en los pueblos que conforman los municipios de Tapalpa y Amacueca, es donde ocurrió la aparición del Demonio con la forma de un toro negro de ojos rojos. Foto tomada el 29 de diciembre de 2019.

presente inmediato de las personas que se apropian de esta figura del imaginario, en este caso la aparición de lienzos de piedra, bardas de alrededor de metro y medio realizadas con piedras amontonadas que poco a poco están desapareciendo de estos poblados (ver figura 3), que en este relato sirve como guarida y área de resguardo del Diablo, quien no puede soportar escuchar las oraciones y los rezos en honor a Dios y a la Virgen y se ve obligado a meterse en los espacios existentes entre las rocas.

\section{A MANERA DE CONCLUSIÓN}

A partir de los relatos, se puede tener una idea de la manera en que se representa la figura del Diablo en esta región mexicana, dándonos así un indicio de cómo esta clase de tradiciones compartidas son un elemento para pensar que estamos ante una región folclórica. Al mismo tiempo se aprecia la manera en que se resignificó este personaje del imaginario religioso de acuerdo a las condiciones de vida de los moradores de esta región, viéndose así el mecanismo por el cual se retroalimentan las actividades y espacios de una localidad con sus imaginarios. Se observan diversas cuestiones en torno a la representación del Demonio en la zona sur de Jalisco:

1. La naturaleza mercantil, que obligaba a hombres y mujeres a moverse de sus poblaciones a otras cercanas, que inspiró a la materialización de sus miedos a los peligros de la noche en la figura del Demonio, utilizando para su creación 
aspectos reconocibles de este personaje de la mitología del cristianismo, pero adaptados a las condiciones de vida de estos pobladores.

2. Se ven elementos del Diablo barroco novohispano, es decir el que llegó a estas tierras con los evangelizadores y conquistadores europeos, demostrándonos una vez más la facilidad que esta figura del imaginario ha tenido para adaptarse y reconfigurarse en distintos espacios, por el éxito que tiene como personaje representativo del mal y los terrores populares, en este caso siendo visto como un ente tanto maléfico como burlón.

3. Este análisis nos muestra la naturaleza mestiza de estos relatos folclóricos que retoman elementos de la tradición europea, resignificándolos en el contexto mexicano, ya no del período colonial sino del presente casi inmediato.

Finalmente, también se hace este análisis para sacar a la luz estos relatos, de esta región de Jalisco, que han sido poco rescatados por otros folcloristas, filólogos, antropólogos e historiadores de las religiones, siendo este trabajo, a su vez, una invitación a ser analizados e investigados con mayor atención.

Archivos consultados

AHAG = Archivo Histórico de la Arquidiócesis de Guadalajara (México)

\section{BiBLIOGRAFÍA}

Ayala Calderón, Javier (2010): El Diablo en la Nueva España, México, Universidad de Guanajuato.

Briggs, Katharine M. (ed.) (2019): Cuentos populares británicos, Juan Antonio Molina Foix (trad.), Madrid, Siruela (Biblioteca de cuentos populares).

Carranza Vera, Claudia (2014): «La lucha contra el Diablo en algunos ejemplos de la narrativa tradicional mexicana», en Temas y motivos en formas narrativas de la literatura tradicional de México, Carranza Vera, Claudia y Zavala Gómez del Campo, Mercedes (eds.), México, Colsan, pp. 137-153.

Delgado Linacero, Cristina (1996): El toro en el Mediterráneo, Madrid, Universidad Autónoma de Madrid.

Delgado Linacero, Cristina (2007): Juegos taurinos en los albores de la historia, Madrid, Egartorre libros.

Flores, Enrique y MASERA, Mariana (coords.) (2010): Relatos populares de la Inquisición novohispana. Rito, magia y otras «supersticiones», siglos XVII-XVIII, Madrid, CSIC.

Martínez Morales, José Luis (2006): «¿Literatura regional en tiempos de globalización?», en Investigación literaria y región, Betancourt, Ignacio (coord.), México, COLSAN, pp. 11-27.

Michelet, Jules (2009): La bruja. Un estudio de las supersticiones en la Edad Media, Rosina Lajo y Victoria Frigola (trads.) (cuarta edición), Madrid, Akal (Colección básica de bolsillo).

Muchembled, Robert (2011): Historia del Diablo. Siglos XII-XX, Federico Villegas (trad.) (cuarta edición), México, FCE (Selección de obras de historia). 
Ramírez GonzÁlez, Martha Isabel (2014): «El Diablo encarnado: la representación del Diablo en leyendas tradicionales de México», en Temas y motivos en formas narrativas de la literatura tradicional de México, Carranza Vera, Claudia y Zavala Gómez del Campo, Mercedes (eds.), México, COLSAN, pp. 155-165.

ZaVAla GómEz Del CAMPO, Mercedes (2013): «Hacia la delimitación de regiones folclóricas en México: la región centro-noreste del Altiplano», en Variación regional en la narrativa tradicional de México, González, Aurelio, Rodríguez Valle, Nieves y Zavala Gómez del Campo, Mercedes (eds.), México, COLSAN, pp. 29-44.

Fecha de recepción: 24 de enero de 2020

Fecha de aceptación: 26 de abril de 2020

$$
\text { i }
$$

